\title{
Gestão do Conhecimento em Bibliotecas Universitárias: estudo bibliométrico na base de dados Web of Science
}

\author{
Leticia Lima de Sousa \\ Universidade Federal do Pará, Departamento de Ciência da Informação, Belém, PA, Brasil \\ $\underline{\text { leticia.sousa@ufra.edu.br }}$ \\ Thiago Henrique Bragato Barros \\ Universidade Federal do Rio Grande do Sul, Departamento de Ciência da Informação, Porto Alegre, RS, \\ Brasil \\ bragato.barros@ufrgs.br \\ Nilzete Ferreira Gomes \\ Universidade Federal Rural da Amazônia, Biblioteca, Belém, PA, Brasil \\ nilzete.gomes@ufra.edu.br
}

DOI: https://doi.org/10.265/rici.v13.n3.28162

Recebido/Recibido/Received: 2019-11-10

Aceitado/Aceptado/Accepted: 2020-06-25

ARTIGOS DE REVISÃO
Resumo: Realizou-se um estudo bibliométrico sobre os trabalhos publicados na temática Gestão do Conhecimento em Bibliotecas Universitárias (BU) no período de 2002 a 2020 na base de dados Web of Science. A metodologia na aplicação da análise bibliométrica usando o modelo de Marschner, Ávila e Sommer (2016) com adaptações. Fez-se uma revisão de literatura sobre a temática, se constatando que só existe o estudo de Bem e Reinisch (2014) que faz análise bibliométrica sobre GC em BU. Foram recuperados 48 trabalhos, dos quais foram analisados somente 33. Foram considerados somente aqueles pertencentes a área de Ciência da Informação e Biblioteconomia. Os resultados apontaram os anos mais produtivos entre 2017 e 2019. Os tipos de documentos são: artigos, early access e trabalhos em eventos, dos quais os artigos constituem a maior parte. O periódico com maior quantitativo de publicações é o Journal of Librarianship and Information Science. Os autores mais produtivos são: Ugwu, De Bem, Ekere e Rossi. As instituições que possuem mais publicações são: Universidade da África do Sul, Universidade da Nigéria e Universidade Federal de Santa Catarina. Os países que detêm um quantitativo maior de publicações são: África do Sul, Índia, Nigéria, Brasil, Paquistão e Espanha. As agências financiadoras são: Delta State University, ICSSR New Delhi, Ministry of Science and Innovation of The Government of Spain e University of Zululand. A produção científica na base é publicada nos idiomas inglês, português e espanhol, mas a principal língua é a inglesa. Conclui-se que os estudos sobre Gestão do Conhecimento em Bibliotecas Universitárias estão crescendo gradativamente e são recentes na base Web of Science.

Palavras-chave: Bibliometria. Análise bibliométrica. Inteligência organizacional.

Gestión del conocimiento en bibliotecas universitarias: estudio bibliométrico en la base de datos Web of Science

Resumen: Se realizó un estudio bibliométrico sobre los trabajos publicados sobre el tema de la Gestión del Conocimiento en las Bibliotecas Universitarias en el período de 2002 a 2020 en la base de datos de Web of Science. La metodología en la aplicación del análisis bibliométrico utilizando el modelo de Marschner, Ávila y Sommer (2016) con adaptaciones. Se realizó una revisión de la literatura sobre el tema, que muestra que solo existe el estudio de Bem y Reinisch (2014) que realiza un análisis biométrico de KM en las BU. Se recuperaron 48 obras, de las cuales solo se analizaron 33. Solo se consideraron las pertenecientes al área de Ciencias de la Información y Biblioteconomía. Los resultados mostraron los 
años más productivos entre 2017 y 2019. Los tipos de documentos son: artículos, acceso temprano y trabajos en eventos, de los cuales los artículos constituyen la mayoría. La revista con el mayor número de publicaciones es el Journal of Librarianship and Information Science. Los autores más productivos son: Ugwu, De Bem, Ekere y Rossi. Las instituciones con más publicaciones son: Universidad de Sudáfrica, Universidad de Nigeria y Universidad Federal de Santa Catarina. Los países con mayor número de publicaciones son: Sudáfrica, India, Nigeria, Brasil, Pakistán y España. Las agencias de financiación son: Delta State University, ICSSR New Delhi, Ministerio de Ciencia e Innovación del Gobierno de España y la Universidad de Zululand. La producción científica en la base de datos se publica en inglés, portugués y español, pero el idioma principal es el inglés. Se concluye que los estudios sobre Gestión del Conocimiento en las Bibliotecas Universitarias están creciendo gradualmente y son recientes en la base Web of Science.

Palabras clave: Bibliometria. Análisis bibliométrico. Inteligencia organizacional.

\section{Knowledge management in academic libraries: bibliometric study on the Web of Science}

Abstract: A bibliometric study was carried out on the works published about Knowledge Management in University Libraries in the period from 2002 to 2020 in the Web of Science database. The methodology in the application of bibliometric analysis using the model of Marschner, Ávila and Sommer (2016) with adaptations. A literature review was made on the subject, showing that there is only the study by De Bem and Reinisch (2014) that does a biometric analysis on KM in BUs. 48 works were recovered, of which only 33 were analyzed. Only those belonging to the area of Information Science and Library Science were considered. The results showed the most productive years between 2017 and 2019. The types of documents are articles, Early access and works in events, of which articles make up the majority. The journal with the highest number of publications is the Journal of Librarianship and Information Science. The most productive authors are: Ugwu, De Bem, Ekere and Rossi. The institutions with the most publications are: University of South Africa, University of Nigeria and Federal University of Santa Catarina. The countries with the largest number of publications are: South Africa, India, Nigeria, Brazil, Pakistan and Spain. Funding agencies are: Delta State University, ICSSR New Delhi, Ministry of Science and Innovation of The Government of Spain and University of Zululand. The scientific production in the database is published in English, Portuguese and Spanish, but the main language is English. It is concluded that studies on Knowledge Management in University Libraries are gradually growing and are recent at the base Web of Science.

Keywords: Bibliometry. Bibliometric analysis. Organizational intelligence.

\section{Introdução}

Compreende-se que a Ciência da Informação (Cl) é interdisciplinar por natureza, relacionando-se com diversas áreas como, por exemplo: a bibliometria e a Gestão do Conhecimento (GC). Desta forma, se realizou um estudo bibliométrico sobre os trabalhos publicados na temática Gestão do Conhecimento (GC) em Bibliotecas Universitárias(BU) no período de 2002 a 2020 (até abril), na base de dados Web of Science, mostrando-se: o total de publicações, áreas temáticas, tipos de documentos, ano das publicações, autores, periódicos, instituições, agências financiadoras, países e idioma.

A problemática da pesquisa foi verificar como estão sendo desenvolvidas as pesquisas na área de GC em BU, no período de 2002 a 2020. Assim foi possível elucidar o cenário atual das pesquisas, verificando aspectos importantes que auxiliam na compreensão do surgimento e desenvolvimento da temática ao longo do tempo. 
A pesquisa organiza-se da seguinte forma: no capítulo dois explana-se sobre a Bibliometria e seu construto teórico; no capítulo três abordam-se os aspectos conceituais a respeito da Gestão do Conhecimento e sobre os estudos bibliométricos na área; já na seção quatro está a Metodologia, onde apresentam-se as etapas referentes ao trabalho; o capítulo cinco expõe a análise e discussão dos resultados dessa pesquisa; o capítulo seis refere-se às considerações finais; e por fim estarão as referências utilizadas nesse trabalho.

\section{Bibliometria}

A consolidação da Bibliometria no cenário brasileiro tem sido constatada pelo aumento expressivo de pesquisas que aplicam a análise bibliométrica em suas investigações científicas. Esta consolidação é evidente mais ainda por sua utilização, cada vez mais frequente, em estudos sobre os aspectos característicos dos campos científicos.

Figueiredo (1993, p. 60) considera a Bibliometria como uma "análise estatística dos processos de comunicação escrita, tratamento quantitativo (matemático e estatístico) das propriedades e do comportamento da informação registrada". Na visão de Macias-Chapula (1998, p. 134), análise bibliométrica "é o estudo dos aspectos quantitativos da produção, disseminação e uso da informação registrada".

Saes (2005) avalia a Bibliometria, como uma forma de quantificar o processo de comunicação registrada, natureza e a evolução dos campos científicos, mediante a contagem e análise das características do processo comunicativo.

A "Bibliometria é o estudo dos aspectos quantitativos da produção, disseminação e uso da informação registrada; desenvolve padrões e modelos matemáticos para medir esses processos, usando seus resultados para elaborar previsões e apoiar tomadas de decisão." (BERNARDINO; CAVALCANTE, 2011, p. 251). Já na visão de Guedes e Borschiver (2005), a bibliometria propicia a tomada de decisão na gestão da informação e do conhecimento, pois auxilia a organização e sistematização das informações científicas.

Boyack, Wylie e Davidson (2002) frisam que os estudos bibliométricos são divididos em dois planos: 1) o macro plano que trabalha com as unidades estruturais básicas de um determinado campo do conhecimento científico, evidenciando suas inter-relações e relacionamentos, em escala ampla; e 2) o microplano que procura explicitar os mapas do conhecimento, em um ramo específico de uma determinada área do conhecimento, a fim de mostrar o estado da arte de determinado assunto.

A bibliometria apresenta um conjunto de leis que a regem, são elas: Lei de Bradford, A Lei de Zipf e Lei de Lotka, vistas a seguir. 
Lei de Bradford, também chamada de Lei da Dispersão "permite, mediante a medição da produtividade das revistas, estabelecer o núcleo e as áreas de dispersão sobre um determinado assunto em um mesmo conjunto de revistas" (VANTI, 2002, p. 153).

A Lei de Zipf, também denominada como Lei do Menor Esforço, consiste na medição de frequência entre as palavras nos textos gerando uma relação de termos provenientes de uma determinada disciplina ou temática. A Lei de Zipf se divide em duas (Quadro 1).

Quadro 1 - Leis de Zipf

\begin{tabular}{|c|l|}
\hline LEIS DE ZIPF & \multicolumn{1}{c|}{ DESCRIÇÃO } \\
\hline Primeira Lei de Zipf & $\begin{array}{l}\text { Afirma que o produto da ordem de série de uma palavra multiplicado pela } \\
\text { frequência de ocorrência era aproximadamente constante. Representada pela } \\
\text { fórmula: } r \text {. } f=c \text {, onde: } r=\text { produto; } f=\text { frequência; } c=\text { constante. }\end{array}$ \\
\hline Segunda Lei de Zipf & $\begin{array}{l}\text { Enuncia que, em um determinado texto, várias palavras de baixa frequência de } \\
\text { ocorrência (alta ordem de série) têm a mesma frequência. }\end{array}$ \\
\hline
\end{tabular}

Fonte: Guedes e Borschiver (2005, p. 6).

A Lei de Lotka conhecida também como Lei do Quadrado Inverso, diz que a quantidade de autores que publicam (n) trabalhos é inversamente proporcional a $n^{2}$. Pode ser entendida como uma função de probabilidade, pois quanto maior o quantitativo de publicações mais fácil é publicar um novo trabalho. Os pesquisadores mais produtivos conseguem maior reconhecimento e estes têm acesso a maiores recursos para o aprimoramento de suas pesquisas (MALTRÁS BARBA, 2003). O Quadro 2 mostra os aspectos das três leis que regulam os estudos bibliométricos.

Quadro 2 - Leis que regem os estudos bibliométricos

\begin{tabular}{|c|c|c|c|}
\hline LEIS & MEDIDA & CRITÉRIO & \multicolumn{1}{|c|}{ OBJETIVO PRINCIPAL } \\
\hline Lei de Bradford & $\begin{array}{c}\text { Grau de atração do } \\
\text { periódico }\end{array}$ & $\begin{array}{c}\text { Reputação do } \\
\text { periódico }\end{array}$ & $\begin{array}{l}\text { Identificar os periódicos mais } \\
\text { relevantes e que dão maior } \\
\text { vazão a um tema em específico. }\end{array}$ \\
\hline Lei de Zipf & $\begin{array}{c}\text { Frequência de } \\
\text { palavras-chave }\end{array}$ & $\begin{array}{c}\text { Lista ordenada de } \\
\text { temas }\end{array}$ & $\begin{array}{l}\text { Estimar os temas mais } \\
\text { recorrentes relacionados a um } \\
\text { campo de conhecimento. }\end{array}$ \\
\hline Lei de Lotka & Produtividade autor & Tamanho-frequência & $\begin{array}{l}\text { Levantar o impacto da produção } \\
\text { de um autor numa área de } \\
\text { conhecimento. }\end{array}$ \\
\hline
\end{tabular}

Fonte: Chueke e Amatucci (2015, p. 3).

\section{Gestão do Conhecimento}

A transição da sociedade industrial para o paradigma da informação e do conhecimento, mudou o interesse que antes estava voltado ao processo de apropriação dos recursos convencionais (terra, trabalho, capital), agora a informação e, mais recentemente o conhecimento, passam a ser os ativos mais importantes (MATTERA, 2014). 
A partir deste cenário, de forma cada vez mais frequente as organizações passaram a se preocupar em gerenciar o capital intangível. O termo "Gestão do Conhecimento" se populariza na década de 1980, contudo, já acontecia no cotidiano das organizações a utilização de experiências acumuladas pelas pessoas e o compartilhamento de conhecimento. Assim, antes do surgimento do próprio termo já se praticava a GC (DALKIR, 2011).

Segundo Valentim (2003) a Gestão do Conhecimento é o conjunto de estratégias para criação, aquisição, compartilhamento e utilização de ativos de conhecimento, bem como o estabelecimento de fluxos que garantam sua disponibilidade no tempo e formato adequados, com a finalidade de auxiliar na geração de ideias, propiciar a solução de problemas e na tomada de decisões.

A GC propicia a criação, aquisição, utilização e compartilhamento do conhecimento tácito, estabelecendo fluxos que garantam sua disponibilidade no tempo e formato adequados, com a finalidade de auxiliar na solução de problemas e permitir a tomada de decisões (MURRAY, 1996; MURRAY; MEYERS, 1997; DAVENPORT; PRUSAK, 1998; SVEIBY, 1998; GURTEEN, 1998; MALHOTRA, 2000; TEIXEIRA FILHO, 2000; BUKOWITZ; WILLIAMS, 2002; DUDZIAK; VILLELA; GABRIEL, 2002; ROSSATO; CAVALCANTI, 2002; KAKABADSE, KAKABADSE, KOUZMIN, 2003).

Portanto, por meio da GC é possível estabelecer uma visão estratégica para a utilização do conhecimento, promovendo sua criação, codificação e transferência, estimulando a criatividade, inovação, aprendizagem e a educação continuada.

Compreende-se assim, que a GC é um conjunto de atividades que promovem a sistematização do conhecimento organizacional permitindo às organizações alcançarem seus objetivos levando ainda ao aumento da competitividade.

Após a compreensão do que vem ser a Gestão do Conhecimento, no contexto mais amplo, se destaca que sua aplicação não se dá unicamente em empresas e instituições, ela pode também ser implementada no ambiente das Bibliotecas Universitárias. A GC em BU "envolve organizar e prover acesso a recursos intangíveis que ajudam os bibliotecários e administradores a desempenhar suas funções de forma mais eficiente e efetivamente" (JANTZ, 2001, p. 34).

Shanhong (2000) explana que a GC em bibliotecas trata os processos de pesquisa e desenvolvimento do conhecimento. Também propicia a criação de estruturas que promovem o conhecimento, troca de experiências entre os colaboradores da biblioteca. A qualificação do corpo técnico se torna essencial para a geração e conversão do conhecimento. Nas BU, a GC apresenta três focos diferenciados: 1. Gestão dos recursos humanos; 2. Promoção da inovação 
do conhecimento; e 3. Incentivo à utilização da tecnologia da informação como ferramenta para a efetivação da GC.

A partir da distinção entre o conceito de GC nas organizações em geral e no contexto das $\mathrm{BU}$, se destaca que muitos estudos foram realizados a fim de analisá-la tanto de forma teórica quanto empírica em ambos os campos. Com o crescimento das pesquisas muitos se dedicaram a realizar estudos bibliométricos a fim de compreendê-los de forma mais precisa, o que será visto na próxima seção.

\subsection{Gestão do conhecimento: estudos bibliométricos}

A GC passa a ser estudada no campo da Bibliometria pelos pesquisadores que perceberam a necessidade de se conhecer mais sobre esse campo. Ambas as áreas passam então a se relacionar na busca por descrever as características da GC, sendo empregada a análise bibliométrica que compreende um conjunto de leis que auxiliam nas investigações.

Nos estudos de Bibliometria referentes à GC na base de dados Web of Science foram identificados os trabalhos a seguir.

Paulista, Campos e Turini (2010) realizaram uma análise bibliométrica sobre GC utilizando a base Web of Science, no período compreendido de 1995 a 2010. Utilizaram o termo "knowledge management" e fazendo os devidos refinamentos na pesquisa, foram considerados para análise somente 3170 documentos.

A partir dos resultados se constatou que os anos com maior número de publicações e citações foram de 2007, 2008, 2009. Foram identificadas: as três primeiras palavras-chave mais utilizadas são "Management", "Knowledge management" e "Knowledge". Os três primeiros autores mais citados Mintzberg H., Nonaka I. e Davenport T. H. O periódico que mais publica é "Acad. Manage J." Os trabalhos clássicos mais citados são Davenport T. H., Nonaka I. e Alavi M. e os mais recentes são Paschke A., Jones W. e Antonacopoulou E. P. Os países mais produtivos são: Estados Unidos da América (EUA), Inglaterra, Taiwan, China, Canadá, Espanha, Austrália, Países Baixos e Itália. É importante frisar que o Brasil ficou na 30ạ colocação no ranking. Concluem afirmando a importância de se realizar pesquisas em outras áreas da Engenharia de Produção e a necessidade de acrescentar periódicos nacionais que não estão na Web of Science na análise bibliométrica.

De Bem e Reinisch (2014) realizaram um estudo bibliométrico utilizando 4 bases de dados, Scopus, Web of Science, LISTA e ISTA, no período de 2007 a 2013. Eles analisaram a produção científica nas áreas de Biblioteconomia e/ou Ciência da Informação associadas à GC. A metodologia consistiu no uso da bibliometria e para a recuperação usaram os termos 
"knowledge management", "information Science", "Library", "Librarian" e "Librarianship", se obtendo 453 documentos relevantes para a pesquisa.

Os resultados mostraram que o periódico mais produtivo é "Library \& Information Update". A maior quantidade de publicações ocorreu no ano de 2008 e os demais, nos anos 2007, 2009, 2010, 2011 e 2012 apresentaram uma quantidade que se manteve equilibrada. Os autores e países que mais publicam são: Austrália (Daneshgar e Martin); Reino Unido (Hyams e Mezey); África do Sul (Ngulube e Onyancha) e Irã (Parirokh, Sarrafzadeh e Hazeri). Entre as palavras-chave mais presentes nos textos estão: bibliotecas, sistemas, organização, aprendizagem e saúde.

Tessecino et al. (2014) também realizou um estudo da GC dentro da Engenharia de Produção na base de dados Web of Science, juntamente com o sistema Web Qualis, abragendo os anos de 2009 a 2014. Utilizaram o termo "Knowledge Management", sendo considerado para análise apenas 2.769 artigos. Os seguintes aspectos foram mapeados: artigos publicados por ano, o estrato qualis dos periódicos, títulos de periódicos que publicaram no mínimo dois artigos por ano, autores que publicaram no mínimo um artigo por ano e os países mais produtivos.

Os resultados apontaram que o ano de maior publicação foi 2009, havendo decréscimo em 2013. A maioria dos periódicos que publica sobre o tema recebeu classificação Qualis A2. O periódico mais produtivo foi "Journal of Knowledge Management". O autor mais produtivo é: Bontis N. O país mais produtivo: é a China. Concluem destacando a importância de se realizar mais estudos sobre a categoria de Engenharia III a fim de contribuir para sua discussão.

Marschner, Ávila, Sommer (2016) analisaram publicações sobre GC e gestão da inovação na base de dados Web of Science, no período de 1945 a 2016. Usaram os termos "knowledge management" e "innovation management", permitindo a recuperação de 372 publicações. Os autores constataram que as publicações sobre a temática só começam a aparecer na base em 2003 e os anos com maior número de trabalhos publicados foram 2008 e 2015. A maioria dos documentos foram publicado na área temática de Economia empresarial e o formato utilizado com maior frequência para publicação são proceedings papers ficando em segundo lugar os artigos. O periódico International Journal of Technology Management é o que possui mais publicações sobre o tema. O autor mais produtivo é An xm e os países que lideram o ranking são China, EUA e Espanha. A instituição que mais produz é "Wuhan University of Technology" na China. O idioma mais usado nas publicações é a língua inglesa. Os autores concluem que esse tipo de estudo é relevante para a comunidade acompanhar a evolução do campo de pesquisa. 
Kovaleski, Azarias e Campos (2017) investigaram as tendências e perspectivas em trabalhos de revisão de literatura e revisão sistemática de literatura sobre GC, no período de 2007 a 2017, utilizando a Web of Science. Foram utilizadas as palavras-chave "Knowledge Management", "Literature Review" e "Systematic Literature Review", sendo considerados pertinentes para a pesquisa somente 80 trabalhos.

Os resultados mostram que os artigos se dividem em: revisão de literatura (63 artigos) e revisão sistemática da literatura (17 artigos). As nações mais produtivas são: países desenvolvidos como: a Inglaterra, EUA, Holanda, Itália, França, Espanha, Suíça, Noruega, Singapura, Taiwan Romênia, Finlândia, Escócia e Austrália. Já os menos produtivos são: Nigéria, Malásia, Brasil e Colômbia. Quanto ao formato de publicação se verificou que a maioria prefere divulgar os resultados de suas pesquisas em: anais de eventos e conferências e apenas uma pequena parte opta pelo formato de artigo para revista. Os trabalhos apresentados em eventos são publicados na maioria no "Fórum Internacional de Dinâmicas de Ativos de Conhecimento" e os artigos estão, em sua maior parte, no "Journal of Knowledge Management". A GC é tratada com mais ênfase na área de negócios e economia. O autor mais citado é: Nonaka e Takeuchi, sendo a obra publicada em 1995 a mais citada pelos pares.

Os autores concluíram que a GC possui grande conexão com a área de tecnologia de informação e tem conseguindo o reconhecimento acadêmico. Contudo, há ausência de estudos inerentes aos fatores humanos ligados à GC.

Em síntese, a partir da análise do conjunto de trabalhos sobre Bibliometria em GC se verifica que distintos períodos foram escolhidos, possibilitando compreender o surgimento e desenvolvimento do campo a partir da investigação sobre a produção científica ao longo do tempo. Se percebeu que apenas o trabalho da De Bem e Reinisch (2014) trata, especificamente, da GC fazendo a relação com o campo da Biblioteconomia e CI.

A partir da compreensão do cenário de pesquisa sobre análise bibliométrica em GC e a constatação da existência de apenas um estudo com foco em BU se procedeu com a investigação nesse campo específico, seguindo os procedimentos metodológicos préestabelecidos.

\section{Metodologia}

Esta pesquisa se classifica quanto ao objetivo em exploratória, que de acordo com Gil (2002, p. 41) visa "proporcionar maior familiaridade com o problema, com vistas a torná-lo mais explícito ou a constituir hipóteses. Pode-se dizer que estas pesquisas têm por objetivo principal o aprimoramento de ideias ou a descobertas de intuições". 
Já em relação ao objeto de estudo, se constitui numa pesquisa bibliográfica, pois se realizou a consulta de diversos materiais já produzidos em relação ao assunto em questão. Segundo Marconi e Lakatos (2003, p. 183), este tipo de estudo "abrange toda bibliografia já tornada pública em relação ao tema de estudo, desde publicações avulsas, boletins, jornais, revistas, livros, pesquisas, monografias, teses, material cartográfico etc."

Empregou-se para o estudo a análise bibliométrica, se caracterizando como uma pesquisa quantitativa. Os procedimentos de pesquisa, constantes no quadro 3 , foram divididos nas seguintes etapas: revisão de literatura, coleta de dados e análise e interpretação dos dados obtidos na pesquisa.

Quadro 3-Procedimento metodológico: etapas

\begin{tabular}{|c|c|c|}
\hline ETAPAS & $\begin{array}{l}\text { PROCEDIMENTO } \\
\text { METODDOLÓGICO }\end{array}$ & EXECUÇÃO \\
\hline 1 & $\begin{array}{l}\text { Revisão de } \\
\text { literatura }\end{array}$ & $\begin{array}{l}\text { Levantamento das pesquisas sobre análise bibliométrica em } \\
\text { Gestão do Conhecimento. }\end{array}$ \\
\hline 2 & Coleta de dados & $\begin{array}{l}\text { 1. Escolha da base Wef of Science; } \\
\text { 2. Escolha dos termos Gestão do Conhecimento e Bibliotecas } \\
\text { Universitárias em língua inglesa; } \\
\text { 3. Combinação dos termos em inglês: "knowledge management" } \\
\text { and "university libraries"; } \\
\text { 4. Utilização do operador booleano "and" para relacionar os dois } \\
\text { termos; } \\
\text { 5. Escolha da opção pesquisa básica na Web of Science; } \\
\text { 6. Utilização das aspas para que a busca e recuperação fossem } \\
\text { mais precisos; } \\
\text { 7. Foi escolhida a opção intervalo personalizado para delimitação } \\
\text { temporal; } \\
\text { 8. Escolheu-se também a opção de busca por tópicos: título, } \\
\text { resumo e palavras-chave; } \\
\text { 9. Foram recuperados } 48 \text { documentos sobre a temática; } \\
\text { 10. Logo após foi realizado o refinamento, escolhendo para } \\
\text { análise somente os documentos na área de: Information } \\
\text { Science Library Science que possuíam } 33 \text { documentos; e } \\
\text { 11. Foi utilizado o modelo conceitual de Marschner, Ávila e } \\
\text { Sommer (2016) para a análise bibliométrica incluindo mais } \\
\text { uma característica no modelo referente ao idioma das } \\
\text { publicações. }\end{array}$ \\
\hline 3 & $\begin{array}{l}\text { Análise e discussão } \\
\text { dos dados }\end{array}$ & $\begin{array}{l}\text { Interpretação dos dados obtidos na pesquisa feita na base se } \\
\text { analisando as características gerais das publicações, expondo por } \\
\text { meio de gráficos e quadros explicativos e discutindo-se a partir da } \\
\text { revisão de literatura. }\end{array}$ \\
\hline
\end{tabular}

Fonte: Elaboração própria (2020).

\section{Análise e discussão dos resultados}

Apresenta-se a seguir no quadro 4 , os resultados obtidos pela análise bibliométrica na base Web of Science, no período de 2002 a 2020 (abril). 
Quadro 4 - Frequência de estudos por área temática

\begin{tabular}{|l|c|}
\hline \multicolumn{1}{|c|}{ ÁREAS TEMÁTICAS } & FREQUÊNCIA \\
\hline Information Science Library Science & 33 \\
\hline Management & 7 \\
\hline Computer Science Information Systems & 4 \\
\hline Business & 3 \\
\hline Computer Science Theory Methods & 3 \\
\hline Education Educational Research & 3 \\
\hline Computer Science Interdisciplinary Applications & 2 \\
\hline Engineering Electrical Electronic & 2 \\
\hline Automation Control Systems & 1 \\
\hline Computer Science Software Engineering & 1 \\
\hline Economics & 1 \\
\hline Engineering Civil & 1 \\
\hline Engineering Mechanical & 1 \\
\hline Instruments Instrumentation & 1 \\
\hline Literature & 1 \\
\hline Operations Research Management Science & 1 \\
\hline Psychology Applied & 1 \\
\hline Social Sciences Interdisciplinary & 1 \\
\hline
\end{tabular}

Fonte: Elaborado pelos autores (2020).

Dentre as áreas relacionadas, no Quadro 4, foram escolhidos para análise bibliométrica somente os estudos que se encontram dentro do campo "Information Science Library Science". Foram analisados 33 documentos, verificando que a temática só fica mais frequentes na base a partir de 2015, apresentando maior quantitativo nos anos de 2017 e 2019.

Constata-se então que, o aparecimento e intensificação do quantitativo de publicações aconteceu de forma recente na Web of Science, isso também foi constatado nos estudos de Paulista, Campos e Turini (2010), Tessecino et al. (2014) e Marschner, Ávila, Sommer (2016), que embora tratando sobre GC de forma mais abrangente chegaram a resultados semelhantes aos desta pesquisa.

A intensificação das publicações ocorre a partir de 2003, e em alguns momentos não houve textos publicados na base sobre essa temática, como nos anos de 2002, 2004 a 2009, assim como também aconteceu em 2011 e 2012 (Quadro 5). 
Quadro 5 - Número de estudos publicados por ano

\begin{tabular}{|c|c|}
\hline ANO & $\mathbf{N}^{\circ}$ DE ESTUDOS \\
\hline 2020 & 1 \\
\hline 2019 & 7 \\
\hline 2018 & 4 \\
\hline 2017 & 7 \\
\hline 2016 & 5 \\
\hline 2015 & 3 \\
\hline 2013 & 2 \\
\hline 2010 & 3 \\
\hline 2003 & 1 \\
\hline
\end{tabular}

Fonte: Elaborado pelos autores (2020).

Com relação aos tipos de publicações se verifica que são constituídos de: artigos, trabalhos apresentados em eventos, artigos e uma modalidade denominada Early access (artigos que ainda serão publicados nas revistas, mas que já possuem uma versão prévia disponível).

Analisando, quantitativamente, os formatos escolhidos para publicação, se observa que a maior parte da produção sobre o tema é publicada sob o formato de artigo. Isso diverge dos resultados obtidos por Marschner, Ávila, Sommer (2016) e Kovaleski, Azarias e Campos (2017) que constataram em suas pesquisas um maior número de produção no formato de trabalhos apresentados em eventos científicos (Gráfico 1).

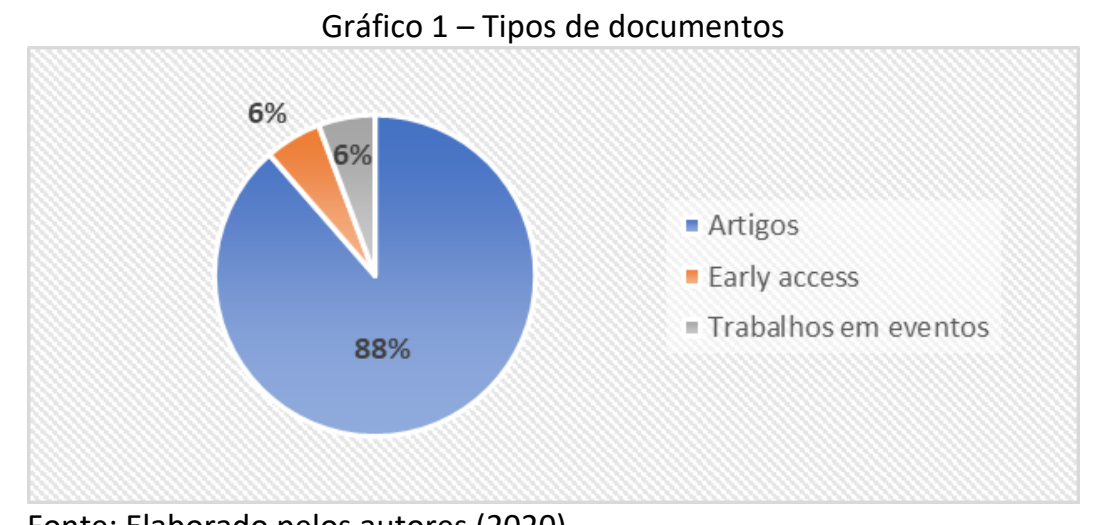

Fonte: Elaborado pelos autores (2020).

Os periódicos que possuem mais publicações sobre a temática são: Journal of Librarianship and Information Science, Electronic Library, DESIDOC Journal of Library Information Technology, IFLA Journal International Federation of Library Associations, Journal o Information Knowledge Management, Library Management e Revista Ibero Americana de Ciência da Informação (Quadro 6). 
Quadro 6-Periódicos científicos que mais publicam sobre GC em Bus

\begin{tabular}{|l|c|}
\hline \multicolumn{1}{|c|}{ PERIÓDICOS } & N DE TRABALHOS \\
\hline Journal of Librarianship and Information Science & 5 \\
\hline Electronic Library & 3 \\
\hline DESIDOC Journal of Library Information Technology & 2 \\
\hline IFLA Journal International Federation of Library Associations & 2 \\
\hline Journal of Information Knowledge Management & 2 \\
\hline Library Management & 2 \\
\hline Revista Ibero Americana de Ciência da Informação & 2 \\
\hline
\end{tabular}

Fonte: Elaborado pelos autores (2020).

Os autores que mais publicam sobre o assunto na Web of Science são: Ugwu (da Universidade da África do Sul, com 7 publicações), De Bem (da Universidade Federal de Santa Catarina, com 3 documentos na base), Ekere (Universidade da Nigéria, com 2 publicações) e Rossi (Universidade de Auckland, em Nova Zelândia, também com 2 trabalhos publicados) (Quadro 7).

Quadro 7 - Autores que possuem mais trabalhos na base sobre GC em BU

\begin{tabular}{|l|c|}
\hline \multicolumn{1}{|c|}{ AUTORES } & $\mathbf{N}^{\circ}$ DE ESTUDOS \\
\hline Ugwu, C. I. & 7 \\
\hline De Bem, R. M. & 3 \\
\hline Ekere, J. N. & 2 \\
\hline Rossi T. & 2 \\
\hline
\end{tabular}

Fonte: Elaborado pelos autores (2020).

Em relação às instituições que mais possuem estudos sobre GC em BU na Web of Science, temos as seguintes: Universidade da África do Sul, Universidade da Nigéria e Universidade Federal de Santa Catarina, conforme se observa no Quadro 8. As duas primeiras Universidades estão situadas em países pertencentes ao continente africano e a terceira instituição pertence à cidade de Santa Catarina, no Brasil (Gráfico 2).

Gráfico 2 - Instituições que publicam sobre GC em BU

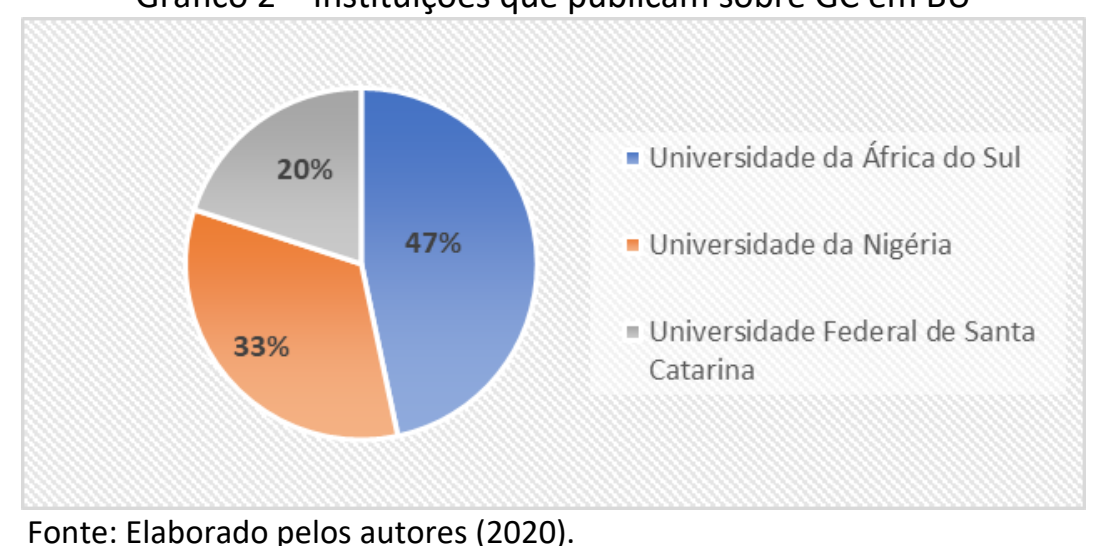

Fonte: Elaborado pelos autores (2020). 
Os países que que possuem maior quantitativo de publicações na Web of Science são: África do Sul, índia, Brasil, Paquistão e Espanha. Isso mostra que a produção em sua maioria é de autores oriundos de nações em desenvolvimento, com exceção da Espanha que é uma nação desenvolvida.

Esses resultados corroboram com os estudos de De Bem e Reinisch (2014), no qual a África do Sul aparece como um dos mais produtivos. Os trabalhos de Kovaleski, Azarias e Campos (2017), Paulista, Campos e Turini (2010) e Marschner, Ávila, Sommer (2016) identificaram também alguns dos países apontados nessa pesquisa. $O$ primeiro identificou a Espanha, Nigéria e Brasil e o segundo e terceiro identificaram a Espanha, como um dos países mais produtores. Isso evidencia o reconhecimento da necessidade da adoção da GC no contexto das BU em não só em países desenvolvidos como também naqueles que estão em crescimento (Gráfico 3).

Gráfico 3 - Países que publicam sobre GC em BU

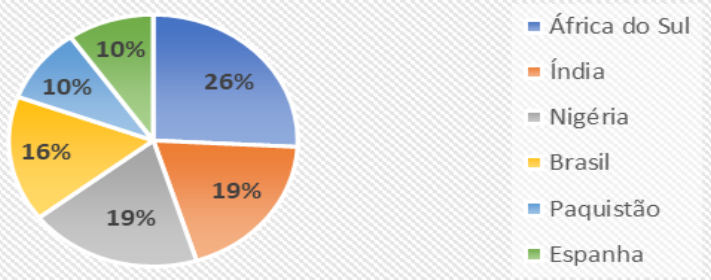

Fonte: Elaborado pelos autores (2020).

Quanto às instituições financiadoras se observou que há quatro agências fomentadoras, tais como: Delta State University, ICSSR New Delhi, Ministry of Science and Innovation of The Government of Spain e University of Zululand (Quadro 8).

Quadro 8 - Agências financiadoras

\begin{tabular}{|c|}
\hline Delta State University \\
\hline ICSSR New Delhi \\
\hline Ministry of Science and Innovation of The Government of Spain \\
\hline University of Zululand \\
\hline
\end{tabular}

Fonte: Elaborado pelos autores (2020)

Quanto ao idioma da publicação, o mais constante é o inglês, infere-se que isso acontece devido ao fato de ser a língua universal para a comunicação científica entre os pares como apontou também a pesquisa de Marschner, Ávila, Sommer (2016). Existem também publicações em português e espanhol, em menor quantidade, conforme se observa no Gráfico 4. 


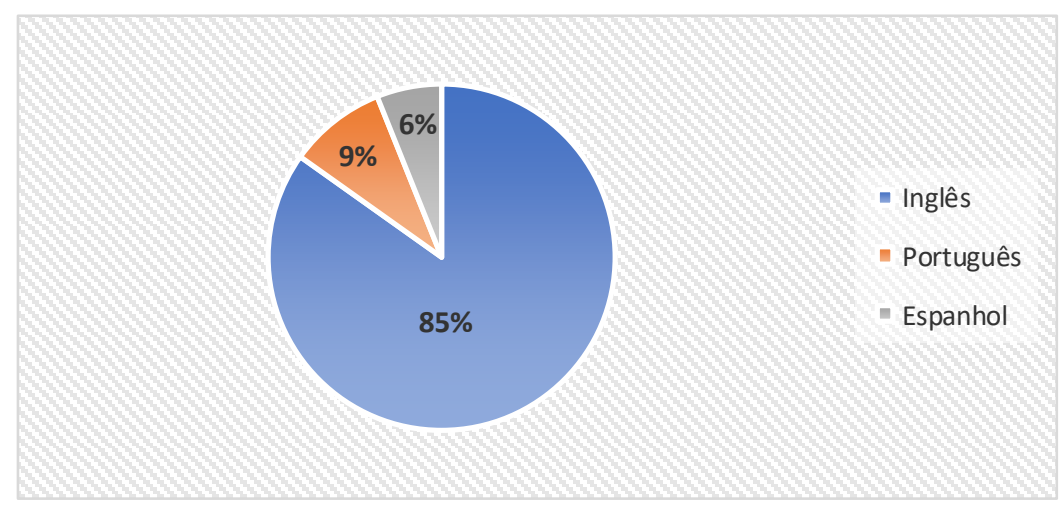

Fonte: Elaborado pelos autores (2020).

Quanto ao fato de as nações em desenvolvimento serem a maioria que pesquisa sobre a temática, isso é algo que se mostra distinto da GC em organizações. De acordo com a pesquisa de Kovaleski, Azarias e Campos (2017) países desenvolvidos têm produzido sobre GC mais do que as nações em desenvolvimento.

Em síntese, como se pode observar a produção sobre a temática apresentou maior quantitativo nos anos de 2016, 2017 e 2019. Foram analisados, especificamente, a produção no campo da "Information Science Library Science" constituídos por 33 documentos e grande parte são publicados no formato de artigos e trabalhos apresentados em eventos. O periódico científico que mais publica é o "Journal of Librarianship and Information Science". Percebeu-se que quatro pesquisadores são os mais produtivos, inclusive, há uma autora brasileira também entre estes. Constatou-se também que há três instituições que possuem maior quantitativo de produção sobre o assunto, havendo também uma instituição brasileira. Quanto aos países produtores se observa que a África do Sul é o país com mais publicações. Há também quatro agências de financiamento no campo de pesquisa e o idioma mais usado é o inglês.

\section{Considerações finais}

O estudo bibliométrico no campo da GC BU mapeou a produção científica sobre o tema, de 2002 a 2020 (até abril), na base de dados Web of Science. Infere-se que o cenário da GC em BU se intensificou recentemente, pois como ficou evidente, as pesquisas publicadas na base aparecem em maior quantitativo somente a partir de 2016. A pesquisa constatou que os países que mais têm produzido sobre o assunto é a África do Sul e Nigéria. O Brasil também apresentou produção sobre a temática, a qual vem crescendo gradativamente.

Na sociedade da informação e do conhecimento, aquelas bibliotecas que gerenciam o conhecimento produzido são mais competitivas, porque isso auxilia a gestão estratégica para 
tomar iniciativas que possam contribuir de forma mais efetiva para o cumprimento da missão das universidades, das quais fazem parte.

O conhecimento intangível é essencial para o crescimento e fortalecimento da organização. Isso tem sido objeto de investigação por parte dos pesquisadores, levando à intensificação de trabalhos que tratam sobre a temática.

Verificou-se se ainda, a partir da revisão de literatura sobre o tema, que só existe um trabalho sobre estudos bibliométricos de GC em BU especificamente, outras pesquisas tratam da temática em geral, outras vertentes da GC. Constatou-se que a produção científica sobre a temática está mais concentrada na área da $\mathrm{Cl}$ e Biblioteconomia, evidenciando que o tema vem sendo abordado com mais frequência dentro destas áreas. Recomenda-se para pesquisas futuras, estudos mais amplos, com a adoção de duas ou mais bases de dados, a fim de propiciar uma visão ampliada do estado atual da produção científica no campo da Gestão do Conhecimento relacionada às Biblioteca Universitárias.

\section{Referências}

BERNARDINO, M. C. R.; CAVALCANTE, R. S. Análise de citações dos artigos da revista Ciência da Informação no período de 2000-2009. Em Questão, Porto Alegre, v. 17, n. 1 p. 247-263, jan./jun. 2011. Disponível em: http://seer.ufrgs.br/EmQuestao/article/view/18601 Acesso em: 15 dez. 2018.

BOYACK, K. W.; WYLIE, B. N.; DAVIDSON, G. S. Domain visualization using VxInsight ${ }^{\circledR}$ for science and technology management. Journal of the American Society for Information Science and Technology, New York, v. 53, n. 9, p. 764-774. 2002.

BUKOWITZ, W. R.; WILLIAMS, R. L. Manual de gestão do conhecimento: ferramentas e técnicas que criam valor para a empresa. 2. ed. rev. Porto Alegre: Bookman, 2002.

DE BEM, R. M.; REINISCH, C. C. S. Gestão do conhecimento, Ciência da Informação e Biblioteconomia: uma análise bibliométrica da produção científica. Revista Digital de Biblioteconomia e Ciência da Informação, Campinas, v. 12, n. 2, p. 38-58, maio/ago. 2014. Disponível em: https://periodicos.sbu.unicamp.br/ojs/index.php/rdbci/article/view/1602/pdf 6 Acesso em: 19 dez. 2018.

CHUEKE, G. V.; AMATUCCI, M. O que é bibliometria? uma introdução ao Fórum. Revista Eletrônica de Negócios Internacionais, São Paulo, v.10, n. 2, p. 1-5, maio/ago. 2015. Disponível em: http://internext.espm.br/internext/article/view/330/233 Acesso em: 15 dez. 2018.

CORREA, F.; ZIVIANI, F.; CHINELATO, F. B. Perspectivas em Gestão \& Conhecimento, João Pessoa, v. 6, n. 2, p. 204-217, jul./dez. 2016. Disponível em: http://www.periodicos.ufpb.br/ojs2/index.php/pgc/article/view/27943/16527 Acesso em: 10 dez. 2018. 
DALKIR, Z. Knowledge Management in theory and practice. 2nd ed.. Cambridge: MIT, 2011.

DAVENPORT, T. H.; PRUSAK, L. Conhecimento empresarial: como as organizações gerenciam o seu capital intelectual. Rio de Janeiro: Campus, 1998.

DUDZIAK, E. A.; VILLELA, M. C. O.; GABRIEL, M. A. Gestão do Conhecimento em Bibliotecas Universitárias. In: SEMINÁRIO NACIONAL DE BIBLIOTECAS UNIVERSITÁRIAS, 12., 2002, Recife. Anais [...] Recife: Universidade Federal de Pernambuco, 2002, p. 1-12.

FIGUEIREDO, N. M. Desenvolvimento e avaliação de coleções. Rio de Janeiro: Rabiskus, 1993.

GIL, A. C. Como elaborar projetos de pesquisa. 4. ed. São Paulo: Atlas, 2002.

GUEDES, V. L. S.; BORSCHIVER, S. Bibliometria: uma ferramenta estatística para a gestão da informação e do conhecimento, em sistemas de informação, de comunicação e de avaliação científica e tecnológica. In: ENCONTRO NACIONAL DE CIÊNCIA DA INFORMAÇÃO, 6., 2005, Salvador. Anais [...]. Salvador: ANCIB, 2005. Disponível em: www.cinform.ufba.br/vi anais/docs/VaniaLSGuedes.pdf Acesso em: 28 nov. 2018.

GURTEEN, D. Knowledge, creativity and innovation. Journal of knowledge Management, Bingley, v. 2, n. 1, p. 5-13, jun. 1998.

JANTZ, R. Knowledge management in academic libraries: special tools and processes to support information professionals. Reference Services Review, California, v. 29, n. 1, p. 33-39, February 2001.

KAKABADSE, N. K.; KAKABADSE, A.; KOUZMIN, A. Reviewing the knowledge management literature: towards a taxonomy. Journal of Knowledge Management, England, v. 7, n. 4, p. 7591, apr. 2003.

KOVALESKI, A.; AZARIAS, J. G.; CAMPOS, F. C. Gestão do conhecimento: uma análise bibliométrica sobre publicações de revisão. In: CONGRESSO BRASILEIRO DE ENGENHARIA DE PRODUÇÃO, 7., 2017, Ponta Grossa. Anais [...]. Ponta Grossa: APREPRO, 2017. Disponível em: https://www.researchgate.net/publication/322799330 Gestao do Conhecimento uma Anali se Bibliometrica sobre publicacoes de revisao Acesso em: 18 dez. 2018.

MACIAS-CHAPULA, C. A. O papel da informetria e da cienciometria e sua perspectiva nacional e internacional. Ciência da Informação, Brasília, v. 27, n. 2, p. 134-140, maio/ago. 1998. Disponível em: http://www.scielo.br/pdf/ci/v27n2/macias.pdf Acesso em: 14 dez. 2018.

MALHOTRA, Y. Knowledge management \& new organization forms: a framework for business model innovation. Information Resources Management Journal, United States, v. 13, n. 1, p.54, Jan./mar. 2000. Disponível em: http://www.brint.org/KMNewOrg.pdf Acesso em: 02 out. 2018.

MALTRÁS BARBA, B. Los indicadores bibliométricos: fundamentos y aplicación al análisis de la ciencia. Gijón: Trea, 2003.

MARCONI, M. de A. M.; LAKATOS, E. M. Fundamentos de metodologia científica. 5. ed. São Paulo: Atlas, 2003. 
MARSCHNER, P. F.; ÁVILA, L. V.; SOMMER, A. T. Gestão do conhecimento e gestão da inovação: um estudo bibliométrico na Web of Science: 1945-2015. Revista do CEPE, Santa Cruz do Sul, n. 44,
p. 113-126,
jul./dez.
2016.
Disponível
em:

https://online.unisc.br/seer/index.php/cepe/article/view/8251/5481 Acesso em: 10 dez. 2018.

MATTERA, T. C. Gestão do conhecimento na prática. In: SOUTO, Leonardo Fernandes (org.). Gestão do conhecimento: práticas e reflexões. Rio de Janeiro: Interciência, 2014. p. 199-220.

MURRAY, P. C. New language for new leverage: the terminology of knowledge management. [S. I.: s.n.], 1996.

MURRAY, P. C.; MEYERS, A. The facts about knowledge. Information strategy: the Executive's Journal, United States, v. 2, n. 7, p. 29-33, Sept. 1997.

PAULISTA, P. H.; CAMPOS, D. F.; TURRINI, J. B. Análise bibliométrica da gestão do conhecimento. In: ENCONTRO NACIONAL DE ENGENHARIA DE PRODUÇÃO, 30., 2010, São Paulo. Anais [...]. São Paulo: Enegep, 2010. p. 1-12. Disponível em: http://www.abepro.org.br/biblioteca/enegep2010 tn stp 120784 17263.pdf Acesso em: 13 nov. 2018.

ROSSATO, M. A.; CAVALCANTI, M. Um novo modelo de Gestão do Conhecimento. In: CONGRESSO BRASILEIRO DE GESTÃO DO CONHECIMENTO, 1., 2002, São Paulo. Anais [...]. São Paulo: SBGC, 2002. p. 27701-27715.

SABADIN, M.; MOZZATO, A. R. Por onde anda a gestão do conhecimento? pesquisa bibliométrica em periódicos nacionais: 1999-2015. In: ENCONTRO DE ESTUDOS SOBRE EMPREENDEDORISMO E GESTÃO DE PEQUENAS EMPRESAS, 9., 2016, Passo Fundo. Anais [...]. Passo Fundo: ANEGEPE, 2016. p. 1-15. Disponível em: https://www.egepe.org.br/2016/artigosegepe/501.pdf Acesso em: 15 dez. 2018.

SAES, S. G. Aplicação de métodos bibliométricos e da "Co-Word Analysis" na avaliação da literatura científica brasileira em ciências da saúde de 1990 a 2002. Orientador: Augusto Hasiak Santo. 2005. 183 f. Tese (Doutorado em Saúde Pública) - Faculdade de Saúde Pública, Universidade de São Paulo, $2005 . \quad$ Disponível em: http://www.teses.usp.br/teses/disponiveis/6/6132/tde-13112007-180403/pt-br.php Acesso em: 15 dez. 2018.

SANTOS, B. M. M. et al. Perfil dos autores na produção científica em gestão do conhecimento: uma análise bibliométrica. G\&A, João Pessoa, v. 6, n. 1, p. 44-57, jan./jun. 2017. Disponível em: http://www.periodicos.ufpb.br/ojs/index.php/mpgoa/article/view/34414 Acesso em: 28 de dez. 2018.

SHANHONG, T. Knowledge management in libraries in the 21st century. In: IFLA COUNCIL AND GENERAL CONFERENCE, 66., 2000, Israel. Anais [...]. Israel: IFLA, 2000. Disponível em: http://www.ifla.org/IV/ifla66/papers/057-110e.htm Acesso em: 07 mar. 2004.

SVEIBY, K. E. A nova riqueza das organizações: gerenciando e avaliando patrimônio de conhecimentos. 4. ed. Tradução: Luiz Euclydes Trindade Frazão Filho. Rio de Janeiro: Campus, 1998. 
TEIXEIRA FILHO, J. Gerenciando conhecimento: como a empresa pode usar a memória organizacional e a inteligência competitiva no desenvolvimento de negócios. Rio de Janeiro: Senac, 2000.

TESSECINO, C. Z. et al. Uma análise bibliométrica sobre a gestão do conhecimento na área de engenharia de produção. Revista de Ciência \& Tecnologia, Piracicaba, v. 17, n. 34, p. 93-111, jan./jun. 2014. Disponível em: https://www.metodista.br/revistas/revistasunimep/index.php/cienciatecnologia/article/view/2145/1288 Acesso em: 27 dez. 2018.

VALENTIM, M. L. P. et al. O processo de inteligência competitiva em organizações. Data Grama Zero: Revista de Ciência da Informação, Rio de Janeiro, v. 4, n. 3, p. 1-23, ago. 2003. Disponível em: http://www.brapci.ufpr.br/brapci/ repositorio/2010/01/pdf f589d25523 0007468.pdf Acesso em: 24 set. 2017.

VANTI, N. A. P. Da bibliometria à webometria: uma exploração conceitual dos mecanismos utilizados para medir o registro da informação e a difusão do conhecimento. Ciência da Informação, Brasília, DF, v. 31, n. 2, p. 152-162, maio/ago. 2002. Disponível em: http://www.scielo.br/pdf/ci/v31n2/12918.pdf Acesso em: 10 dez. 2018. 